\title{
Talaşlı İmalat Sektöründe Nesnelerin İnterneti ve Anlık Veri Analizi Yöntemleri Kullanarak Üretim Etkinliğinin Artirılması
}

\author{
Can Aydın ${ }^{1} \quad$ Bahadır Aktaş ${ }^{2}$
}

Öz

Geleceğin üretim sektörünü geleneksel olandan ayırt eden otonom robotlar, nesnelerin interneti ve veri analitiği teknolojileri olacaktır. Bu hedefler doğrultusunda kurumsal dönüşüm süreçleri gerçekleştirilecektir. Buna karşılık ülkemiz de birçok küçük ve orta ölçekli üretici, üretim süreçlerinde üretim verilerini hala kâğıtlara kaydederek sakladığı görülmektedir. Bunun sonucunda tüm bu saklanan veriler karar verme süreçlerine de dâhil edilememektedir. Verilerin otomasyonlar kullanılarak dijital ortamda tutulması ve rapor edilmesine yönelik birçok çalışma bulunmasına rağmen verilerin anlık olarak analiz edilip raporlanmasına yönelik çalışma bulunmamaktadır. Anlık veri analizi kullanarak üretim süreçlerinde takip edilebilirliği arttırmak ve bu sayede üretim performansını ve verimliliğin arttırılması amaçlanmaktadır. Çalışma kapsamında üretim süreçlerinde etkinliğin artrıımasına yönelik gömülü sistemler kullanılmış ve uygulama geliştirilmiştir. Yeni sistemin verimliliğinin ölçülmesi için performans verileri ve maliyet verileri kullanılmıştır. Sonuç olarak yeni sistemin kullanıldığı tezgâh aynı özelliklere sahip diğer tezgâha göre daha yüksek bir üretim artışı göstermiştir. Elde edilen sonuçlara göre üretim sürecinde iş akışını ve zaman yönetimini ve karar alma süreçleri iyileştirilecektir.

\section{Anahtar Kelimeler}

Anlık veri analizi • Nesnelerin interneti • Yönetim bilişim sistemleri • Verimlilik ölçümü

\section{Increasing Production Efficiency with Using Internet of Things and Instant Data Analysis Methods on Machining Sector}

\section{Abstract}

Autonomous robots, internet of things and data-analysis technologies will be the distinguishing factors between the future manufacturing industry and the traditional one. On the other hand, many small and medium-sized production companies in Turkey seem to keep their production records on paper within their production processes. As a result, all these stored data cannot be included in the decision-making process. Although there are many studies about storing and reporting data in digital environment using automations, there is no study to analyze and report data instantaneously. This study aims to increase traceability in production processes by using instantaneous data analysis and to increase production performance and productivity as a result of this increment. In the scope of the study, embedded systems were used and an application was developed to increase efficiency in production processes. Performance data has been used to measure productivity in production processes. As a result, the machine in which the new system was used showed a higher production increase than the other machine with the same characteristics. According to these results the workflow, time management and decision making processes can be improved.

\section{Keywords}

Instant data analysis • Internet of things $\bullet$ Management information system $\bullet$ Productivity measurements

\footnotetext{
1 Sorumlu Yazar: Can Aydın (Dr. Öğr. Üyesi), Dokuz Eylül Üniversitesi, Yönetim Bilişim Sistemleri Bölümü, İzmir, Türkiye. Eposta: can.aydin@deu.edu.tr

2 Bahadır Aktaş (Arş. Gör.), Sakarya Üniversitesi, Yönetim Bilişim Sistemleri Bölümü, Sakarya,Türkiye. Eposta: bahadiraktas91@gmail.com Attf: Aydın, C. ve Aktaş, B. (2018), Talaşlı imalat sektöründe nesnelerin interneti ve anlık veri analizi yöntemleri kullanarak üretim etkinliğinin artrilması. Istanbul Business Research, 47(1), 35-47. http://dx.doi.org/10.26650/ibr.2018.47.1.0002
} 
Geçmişten günümüze yenilikçi yaklaşımlar sayesinde su ve buhar enerjisine dayalı mekanik üretim tesislerinin uygulanması, elektrik ve iş bölümüne dayalı seri üretim ve üretim süreçlerinin otomasyonunu sağlayan üç adet endüstri devrimi geçirildi. İçerisinde bulunan dönem ise 4. Endüstriyel devrimin yaşandığı siber-fiziksel sistemlere dayalı üretimin devreye girdiği dönemdir. Bu dönem, gerçekleşen her sanayi devrimi esas olarak üretim faaliyetlerinde verimliliğin artırılmasına ve iş yapış şeklinin geliştirilmesine yöneliktir (Can ve Kıymaz 2016). Endüstri 4.0 akıllı üretim ve üretim süreçlerinin kurulmasına odaklanmaktadır. Geleceğin üretim süreçlerinde fabrikaların hızlı ürün geliştirme, karmaşık ortamlarda esnek üretim ile baş etmesi gerekmektedir (Vyatkin 2007). Endüstri 4.0 tüm süreçlerin otomatize edildiği, fabrika içerisindeki üretim sürecinde insan, makine ve ürünlerin birbirleriyle iletişim içerisinde bulunduğu sistemdir (Brettel vd. 2014). Üretim sürecinde anlık verinin analiz edildiği ve karar vericilere sunulduğu bir ortam yaratılmaktadır. Bunun yanında Endüstri 4.0 ile beraber fabrikalarda üretim süreçlerinde; nesnelerin interneti, büyük veri analizi, anlık karar verme, sanal gerçeklik tabanlı üretim, siber güvenlik kavramları da kendilerine yer bulmaya başlamaktadır (DFKI 2011). Çalı̧sma kapsamında üretim tezgâhlarında Endüstri 4.0 bileşenlerinden; nesnelerin interneti kullanarak anlık veri elde etme, analizi ve aynı zamanda anlık karar verme süreçleri gerçekleştirilmiştir.

Fabrikalarda Endüstri 4.0 süreçlerine geçiş için atılması gereken adımlar kapsamında fabrika bünyesinde verim artışı sağlanmış, iş süreçlerinde esneklik, bilgi teknolojileri (BT) entegre edilmiş, iş süreçleri dijitalleştirilmiştir (Schuh 2014). Endüstri 4.0 ile beraber BT kullanarak üretimde verimliliğin artırılması pek çok işletmenin öncelikli konusu olmuş ve verimlilik ile kazanç sağlanmak önem kazanmıştır. Resmi ILO (2005) verilerine göre ABD'de 1970'den 2005 yılına kadar üretim sektöründeki istihdam düşmekte iken verimlilik artmaktadır. Üretim sektöründe bilgi teknolojisi kullanımının bu sektörde verimlilik artışı sağladığı tespit edilmiştir. 2005 ile 2014 yılları arasında Türkiye'nin yıllık ortalama işgücü verimliliği değişim oranı \%1,64 olarak hesaplanmıştır (Balkan ve Suçimez, 2007). Bu oran 24 OECD ülkesinin ortalaması olan \%3.20'nin altındadır ve Türkiye OECD ülkeleri arasında 2005 - 2014 yılları arasında işgücü verimliliği değişiminde on yedinci sıradadır (Suiçmez 2017) . 2012 yılında 121 ülkenin işgücü verimliliği düzeyi üzerinde yapılan analiz göre Türkiye 43. sıraya gerilemiştir. Ülkemizde endüstri 4.0 benimsenmesi kapsamında bilişim sektörünün Türkiye'deki potansiyelinin artması günümüz dünyas1nın küreselleşmesi ve gelişmesiyle beraber oluşan doğal bir etkendir (Aydın 2012). Bu sonuçlar Türkiye'de verimlilik alanında yeni yaklaşımlar getirilmesi gerektiğini göstermektedir. Bilişim teknolojilerinin işletme verimliliğini arttırdığ 1 Melville ve Kraemer'in 2004 yılında yapılan çalışmada ortaya konulmuştur. Peter Weill'in (1992) yaptığ çalışmada bir valf üretim firmasında BT"ne yapılan yatırım ile firmanın performansı incelenmiş ve verimliliğinin $\operatorname{arttığı~tespit~edilmiştir.~Çalışmada~BT'nin~}$ veriye ulaşım kolaylığının sağlanması firmanın verimliliği üzerindeki etkileri öl- 
çülmüştür. BT'nde hızlı artış üretim sektöründeki firmaların üretim süreçlerinde değişikliklere yol açmıştır. Bu kapsamda üretim bandında BT kullanılması daha çok veri üretilmesi ve bu verilerin raporlanarak üretim süreçlerinde daha etkin karar verilmesine sebep olmaktadır. Üretimin takip edilip iyileştirilmesi, karar verme süreçlerine katk1 sağlanması ve verimliliğin artırılması için BT kullanılmaya başlanılması gibi konularda son yıllarda yapılan birçok çalışma bulunmaktadır (Kang, 2016; Luo, 2017 ). Geçtiğimiz 7 yılda üretim sektörü $\% 40$ büyümüştür fakat veri toplama ve saklama şekli değişmemiştir (Aydın 2015). Üretim süreçlerinde BT kullanılmasına rağmen Türkiye'de birçok küçük ve orta ölçekli üreticilerin, üretim süreçlerinde verilerini hala kâğıtlara kaydederek sakladığ1 görülmektedir. Bunun sonucunda tüm bu saklanan veriler karar verme süreçlerine de dâhil edilememektedir. Verilerin otomasyonlar kullanılarak dijital ortamda tutulması ve rapor edilmesine yönelik birçok çalışma bulunmasına rağmen verilerin anlık olarak analiz edilip raporlanmasına ve karar süreçlerinde kullanılmasına yönelik çalışma bulunmamaktadır. BT ile anlık veri analizi kullanarak üretim süreçlerinde takip edilebilirliği arttırmak ve bu sayede üretim performansını ve verimliliği arttırılması amaçlanmaktadır. Çalışma kapsamında araştırma sorusu olarak talaşlı imalat sektöründe anlık veri analizi kullanılarak üretim süreçlerinde verimliliğin artıp artmayacağı araştırılmıştır. Üretim süreçlerinde verimliliğin ölçülmesi için şirketin girdi ve çıktı verileri kullanılacaktır.

\section{Teorik Çerçeve ve Hipotez}

Ülkemizde üretim sektörü her geçen gün daha çok büyümektedir (İncekara, 2017). Fakat bu büyüme beraberinde BT'nin yeteri kadar etkin kullanılmamasından dolayi; yoğun evrak işleri, toplanamayan veya geriden takip eden performans verileri, takip edilemeyen üretim istasyonu performansı gibi problemleri de beraberinde getirmektedir. Üretim takibinde eski yöntemlerin kullanılması ve kayıtların el ile kâğıtlara aktarılması veya üretim takip sistemlerine operatör tarafindan el ile girilmesi bunun sebeplerindendir. Bilişim teknolojisinden yararlanamayan işletmeler performans takibinde, dolayısıyla yapılan ve yapılacak işlerin gidişatı ile ilgili alınacak kararların alınmasında sıkıntılar yaşamaktadır ve işletmenin verimliliği düşmektedir. Takip edilemeyen ve ölçülemeyen bir üretim süreci iyileştirilemez yaklaşımıyla ilerlenmiş ve iyileştirmek için ölçmeye odaklanılmıştır (). Bu çalışma ile nesnelerin interneti ve anlık veri analizi yöntemleri kullanılarak üretim sürecinde karar vermeyi hızlandırmak ve kolaylaştırmak amaçlanmaktadır. Geriden takip edilen ve anlık olmayan veriler ve performans hesaplamaların geçmişte bırakıp, anlık performans ölçümü ve rapor üretimiyle beraber şirketin verimliliğini artırmayı hedeflenmektedir. Anlık verilerin analizi ve raporlanmasına yönelik çeşitli çalışmalar bulunmaktadır. Bu kapsamda Aktaş (2014) nesnelerin interneti tabanlı veri toplama ve analiz sistemi geliştirmiştir. Platform geliştirilirken Arduino ve Rasperry Pi gibi gömülü sistemler ile çeşitli sensörler kullanılarak veri toplanmış ve anlık olarak analiz edilmiştir. Bir diğer çalışmada Bakır vd. (2014) tarafindan rafinerilerdeki büyük 
verinin gerçek zamanlı analizine yönelik çalışmadır. Çalışmada Hadoop teknolojisi kullanarak sistemdeki oluşan hatalar anlık olarak tespit edilmiştir. Atçı (2015) bir otomobil klima sisteminin kontrolüne yönelik performans analizlerine bağlı olarak deneysel bir çalışma gerçekleştirmiştir. Çalışmada anlık verileri almak için sıcaklık, nem, basınç, debi hava akış sensörleri ile termokuplar kullanılmıştır. Verilerin zamana göre değişimlerinin sistem performansına etkilerini grafik üzerinde incelenmiş ve raporlanmıştır. Üretim süreçlerinde BT'nin kullanımına yönelik literatür incelendiğinde anlık veri analizinin üretim süreçlerinde verimlilik ve performans artışı sağladığı görülmektedir. Bu kapsamda hipotez olarak BT kullanımının verimliliği artırdığı belirlenmiştir.

$\mathrm{H}_{0}$ : "Nesnelerin interneti ile anlık veri analizi ve raporlanması, üretim süreçlerinde verimliliği değiştirmez"

$\mathrm{H}_{1}$ :"Nesnelerin interneti ile anlık veri analizi ve raporlanması, üretim süreçlerinde verimliliği artırır."

Verimlilik ölçümünde günlük çıktının girdiye oranları karşılaştırılmıştır. Verimlilik, bir üretim ya da hizmet sistemi içerisinde elde edilen toplam fiziksel gelirin (üretim sonu$\mathrm{cu}$, çıktı) kullanılan fiziksel gidere (üretim faktörleri, girdi) oranı şeklinde tanımlanabilir (Efil, 2004). Araştırma, İzmir - Kemalpaşa Organize Sanayi bölgesinde bulunan bir şirkette uygulanmıştır. Şirket 1998 yılında $5500 \mathrm{~m}^{2}$ alana kurulmuş ve y1llık 8000 ton dövme kapasitesine sahiptir. Şirkette 15 ' $\mathrm{i}$ beyaz yakalı olmak üzere 100 kişi çalışmaktadır. Talaşlı imalat, dövme gibi işlemlerini bünyesinde gerçekleştiren ve hem yurtiçi hem Almanya, Macaristan, Fransa, Avusturya, İsveç gibi ülkelerde yurtdışı müşterileri bulunan Talaşlı İmalat firmasıdır. Araştırma kapsaminda hazırlanan üretim takip sistemleri 2 adet dövme makinesinin üretimini takip edecektir. Bu dövme makinelerinin ürettiği ürünler ticari araçlar, iş makineleri, tarım makinelerinde kullanılan metal parçalar, şaft kardan ve çeşitli dişlilerdir.

\section{Yöntem}

Performansın ölçümü için deneysel araştırma yöntemlerinden klasik deneysel tasarım metodu kullanılmıştır. Bu yöntem, hazırlanan yazılım ve uygulamanın işletmedeki etkilerini net bir şekilde görmek ve ne derece etkili olduğunu ortaya koymak için seçilmiştir. Bu metotta bir adet deney grubu ve bir adet kontrol grubu vardır. Deney grubuna deneysel uyarıcı verilecek kontrol grubu ise mevcut işleyişini koruyacak ve ardından karşılaştırılacaktır. Deney ve kontrol gruplarına bir ön test uygulanır ve bağımlı değişken ölçülür. Yapılan manipülasyondan sonra son test yapılarak deney grubunun bağımsız değişkeninde gerçekleşen değişimin, bağımsız değişkene olan etkileri gözlemlenir.

Çalışma kapsamında işletmede iki adet dövme makinesi seçilmiştir. Kontrol ve deney grubunun seçimlerinde eşleştirme yöntemi kullanılmıştır. Bu makineler aynı modeldir ve aynı veya benzer parçalar üretmektedir. Ayrıca bu iki makinenin operatörleri de ortaktır ve bir operatör her iki makinede de dönüşümlü olarak çalışabilmektedir. $\mathrm{Bu}$ tezgâhlardan birisine (A Makinesi) ESM-9450 model süreç kontrol cihazı (sayaç) yerleştirilip yazılım kurul- 
muştur ve bu makineden elde edilen üretim miktarları ve üretim performansı anlık olarak fabrikaya yerleştirilmiş ekran ile izlenmekte, üretim verileri ve performansları kaydedilmektedir. Diğer makinenin (B Makinesi) ise yalnızca üretim verileri ve performansları kayıt altına alınmıştır. Araştırmada kullanılan ve üretim performansına olan etkisi ölçülecek deneysel uyarıcı üretim verilerini sensör yardımıyla anlık olarak alan ve fabrikaya yerleştirilen ekranlarda üretim ve performans verilerini gösteren yazılımdır. Bu yazılım ile hem operatörlerin anlık olarak performanslarını görmesini sağlar ve motivasyonun arttırılmas1, hem de üretim şeflerini ve yöneticilerin üretim sirasinda üretim performansından haberdar olmasını sağlayarak karar vermeyi kolaylaştıracak ve hızlandıracak verileri sağlanması amaçlanmaktadır.

Ön test sürecinde A ve B Makinelerinin 2016 y1lı Aralık ayına kadar olan üretim performansı verileri (üretilen miktar / hedef miktar) edinilmiştir. Son test sürecinde ise deneysel uyarıcının uygulandığı tarih olan 1 Aralık 2016 tarihinden 1 Nisan 2017 tarihine kadar olan üretim performans1 verileri kaydedilmiştir. Bu aşamada araştırma konusu olan şirketin boyutu ve performans beklentileri açıklanıp, sonrasında oluşacak performans kriterlerindeki değişim ortaya konulacaktır. Önerilen sistemin kurulması aşamasında sistem yaşam döngüsü kullanılmıştır. Yazılım geliştirme aşamasında ise pek çok yazılım projesinde kullanılan Waterfall modeli kullanılmıştır.

\section{Uygulama Geliştirme}

\section{Analiz}

Sistem geliştirme yaşam döngüsünün ilk aşaması olan analiz kapsamında örnek firmanın iş süreçleri analiz edilmiştir. Üretime geçecek olan bir parçanın dövme aşamasına geçmeden önceki süreçleri incelenmiştir. Bir parçanın üretim aşamasına gelmeden önce sipariş, ham madde temini ve üretim planlama süreçlerinden geçmeleri gerekmektedir. Bu süreçte yaşanan sorunlardan birisi parça üretim sürelerinin doğru tahmin edilememesinden dolayı üretim planlarının gerçeği yansıtmamasıdır (Şekil 1).

Yaşanan sorunlar tezgâhta üretilen malzemelerin üretim kayıtlarının geleneksel yöntem olarak kâğıt kalem ile gerçekleştirilmesidir. Hem kâğıt kalem kullanımı hem de insan faktörü üretim planlamasında birçok sorunlara sebep olmaktadır. Bu kapsamda BT kullanılarak mevcut işleyiş içerisinde üretim kayıtlarının tutulması ve analiz edilmesi

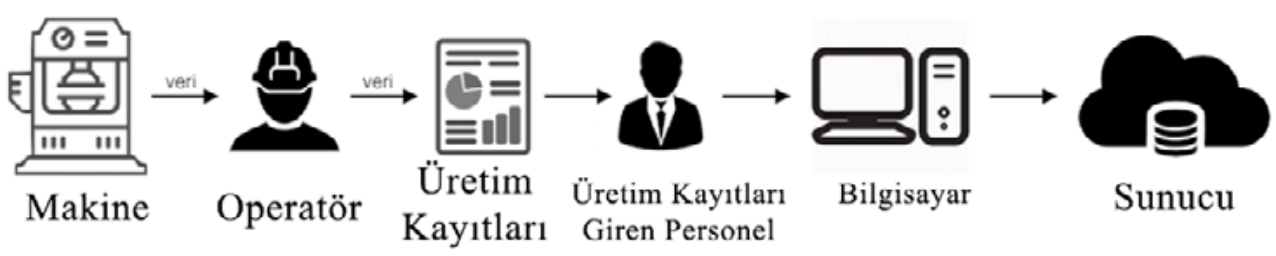

Şekil 1

Mevcut işleyiş 
aşamasında iyileştirme gerçekleştirilecektir. Ayrıca üretim sahasına yerleştirilecek büyük ekranlarda da gösterilecek olan anlık üretim verileri ve performans değerleri, operatörlerin ve vardiya şeflerinin görebileceği bir şekilde yerleştirilecek, böylece anlık kontrol ve motivasyon sağlanması amaçlanmaktadır.

\section{Tasarım}

Sistemin tasarım aşamasında işlevselliğin yanında çalışma ortamı ve bu çalışma ortamında sistemin sürdürülebilir bir yapıda oluşturulması hedeflenmiştir. $\mathrm{Bu}$ kapsamda ilk olarak üretim hattındaki mevcut tezgâhlara nesnelerin interneti cihazları kapsamında veri toplama aşamasında Raspberry Pi gömülü sistemleri kullanılmıştır (Şekil 2). Raspberry Pi cihazının kullanılmasının sebebi dövme fabrikasının titreşimli ve tozlu bir ortam olması ve bu ortamda hareketli parçalı ve soğutma fan1 elektronik cihazların bir koruma ünitesi olmadan çalışmasındaki zorluktur. Yapılan denemelerin ilk aşamasında kullanılan dizüstü bilgisayar tozdan dolayı hasarlan- mıştır. Başka bir faktör ise cihaz boyutunun küçük olmasından dolayı fabrika gibi yoğun ve kalabalık ortamlarda daha kolay monte edilebilmesidir. Verilerin cihazdan elde edilmesi analizi ve veritabanına kaydetmesi için python yazılım dili ile bir uygulama geliştirilmiştir. Son olarak büyük ekran cihazlarda toplanan ve analiz edilen veri görselleştirilmiştir.

Hazırlanan yazılımın sisteme entegrasyonu sonucunda işletmenin iş yapma ve üretim takip etme sürecinde değişiklikler olmuştur. Tasarlanan yeni sistemde operatörün veri girişindeki rolü ortadan kalkmıştır. Operatör sadece üretim makinesini kontrol eder ve operasyonu yönetir. Üretim verisi sayaç yardımıyla okunur ve işletmeye yerleştirilmiş olan gömülü bilgisayara aktarılır. Alınan veri bu gömülü bilgisayarda düzenlenir ve doğruluğu kontrol edilir, daha sonrasında ise veri tabanına kaydedilir. Elde edilen ve veri tabanına kaydedilen üretim verisi, bu veriyi kullanacak olan üretim yönetim yazılımları ve ya sistemleri ile dış sistem entegrasyonu sayesinde paylaşılır. Üretim

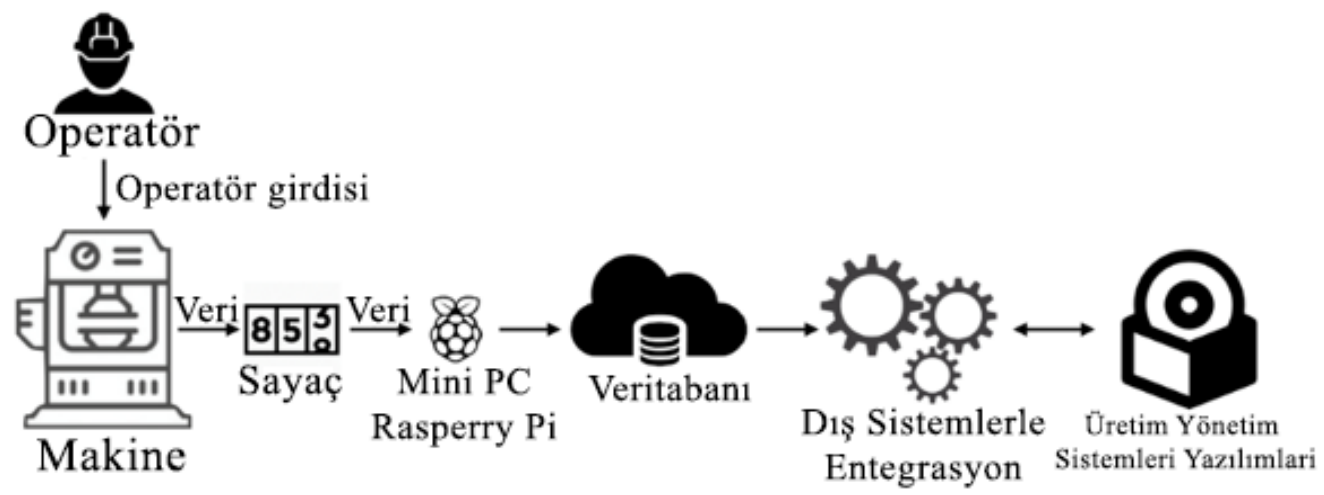

Şekil 2

Sistem tasarımı 
yönetim sistemleri tarafindan oluşturulan iş emirleri ve üretim verileri de diş sistem entegrasyonu ile içe aktarılır.

\section{Veri Toplama}

Sistem tasarımı aşamasında elde edilmek istenilen verilerin toplanması ve saklanması aşamasındaki teknolojik çerçeve ortaya konulmuştur. Sistemin en önemli verisi dövme makinelerinin üretim miktarıdır. Bu veriyi üretim tezgahından almak için sayaç kullanılmıştır. Bunun sebebi kullanılan tezgahlarda sayım yapan herhangi bir devre olmamasıdır. Her bir ürün üretiminde basılan butona yerleştirilen sensör sayesinde sayaca üretim verisi sağlanmıştır. Seçilen sayaç toza dayanıklı bir kutuda geliyor olmas1, standart seri port iletişim prosedürleri kullanması ve hafizası sayesinde toplam üretim sayısı verisini hafizasinda tutabilmesidir.

Sayaçtaki veri RS485-USB dönüştürücüsü kullanılarak bilgisayara iletilmiştir. Seri porttan gönderilen veri akışını anlamlı bir veri olarak almak için algoritma geliştirilmiştir. Algoritma geliştirilirken, seri port iletişimini sağlarken elektrik kesilmesi, sayaç sıfırlanması veya üretimin durması gibi senaryolara karşı önlem almıştır. Seri port ile elde edilen ve ardindan anlamlı hale getirilen bu veriler daha sonrasında veri tabanına kaydedilmiştir. $\mathrm{Bu}$ işlevleri yerine getirecek olan bilgisayar olarak Raspberry pi gömülü bilgisayarları kullanılmıştır.

Python ile hazırlanan seri porttan veri okuma kodunda minimalmodbus, serial kütüphaneleri kullanılarak iletişim yapılacak port seçimi, iletişim hızı seçimi ve ile- tişim kriterleri belirlenmiştir. Seri iletişim 9600 baud-rate hizında ve her bir paket 8 bit büyüklügünde ayarlanarak yapılmıştır. Her bir veri paketinin sonuna 1 adet stop bit adı verilen veri paketinin bittiğini gösteren durdurma biti gönderilmiştir.

Adet sayma programında sensör den okunan yeni adet ve verinin geldiği tezgâh verileri gelmektedir. Uygulama her 1 saniyede tekrar edecek şekilde bir sonsuz döngüye sokulmuştur. Anlık bağlantı kopmaları veya bozuk veri gelmesi durumuna karş1lık önlem amaçlı try - except komutları kullanılmıştır. Bu sayede program yanlış ve anlamsız veri gelmesi durumunda çalışmayı bırakmaz, konsola bir uyarı göndererek çalışmaya devam eder ve hatalı bir işlem yapmaz. Eğer yeni gelen adet, daha önceden sistemde bulunan adet verisinden farkl1 ise yeni okunan adet kaydedilir (Şekil 3).

Adet okuma yazılımı sonucu elde edilen üretim adedi 'Yeni Adet' olarak kaydedilir. Bir önceki okumada kaydedilmiş olan üretim adedi veri tabanından 'Önceki Adet' olarak çekilir. Tezgâhın toplam gerçekleştirdiği üretim miktarı 'Toplam Üretim Adet' olarak çekilir. İlk olarak elde edilen Tezgâh numarasının veri tabanında bulunup bulunmadığ kontrol edilir. Eğer bozuk veya hatalı veriden dolayı yanlış tezgâh numarası alınması durumunda veri tabanına hatalı veri girilmesini engellemek amaciyla böyle bir kontrol yapılmıştır. Daha sonrasında veri tabanında bu tezgâh ile ilişkili üretim verisinin olup olmadığ 1 kontrol edilir. Bu koşul belirtilen tezgâhta yapılan ilk üretimde gerçekleşecektir. Sonrasında veri tabanında 'Önceki Adette veri olacaktır. Bu durumlarda sensör- 


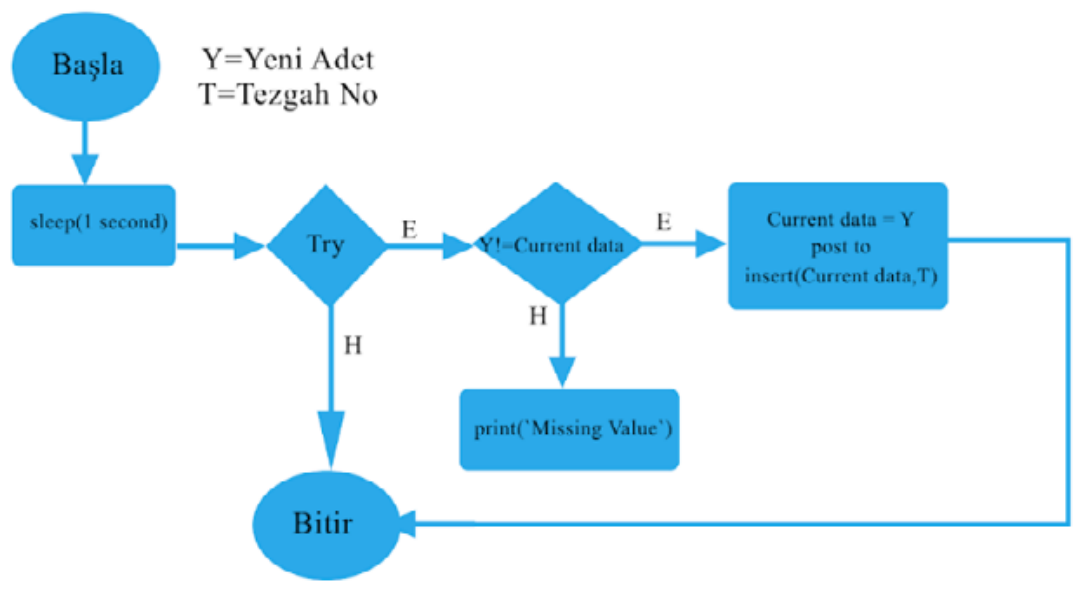

Şekil 3

Tezgahin anlık veri kayıt algoritması

den python kodu yardımıla okunan 'Yeni Adet' ile 'Önceki Âdetin karşılaştırması yapılır. Bu karşılaştırmanın sebebi sensör den gelecek olan verinin el ile sifirlama veya elektrik kesintisi gibi bir aksaklıktan dolayı s1firlanabilecek olması veya iki verinin aynı olmasıdır (Şekil 4). Bu durumlara karşı 3 adet senaryo oluşturulmuştur:

İlk durumda 'Önceki Adet' 'Yeni Adetten daha büyüktür. Bu olması beklenilen durumdur. $\mathrm{Bu}$ durumda üretim miktarındaki fark hesaplatılarak 'Toplam Üretilen Âdete eklenir. İkinci durumda 'Önceki Adet' 'Yeni Adetten daha küçüktür. Bu durum sensör 'ün sıfirlanması durumunda gerçekleşir. Bu durumda 'Yeni Adet' alınıp 'Toplam Üretilen Âdete eklenir. Son durumda ise 'Önceki Adet' ile 'Yeni Adet' birbirine eşittir. $\mathrm{Bu}$ durum iki okuma arasinda herhangi bir üretim olmaması anlamına gelir ve bu koşulun gerçekleşmesi durumunda herhangi bir değişiklik yapılmaz.

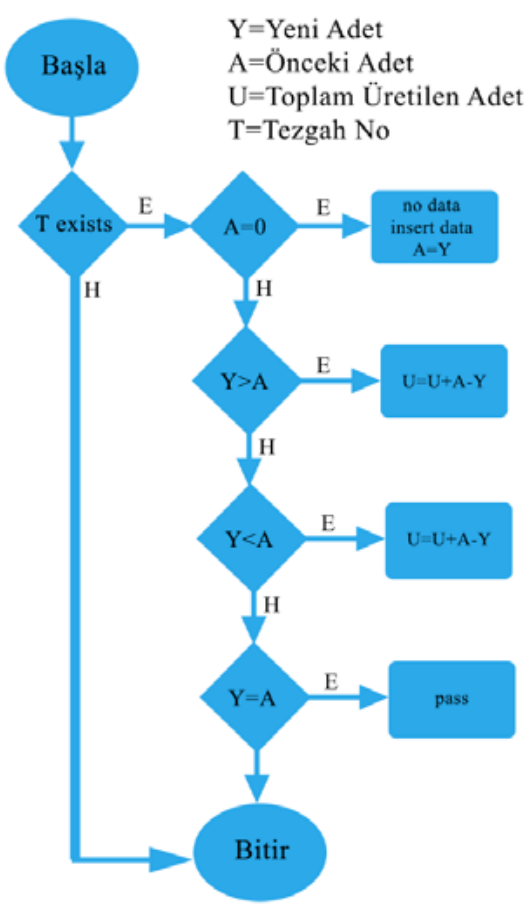
Algoritma sonucunda elde edilen 'Toplam Üretim Miktarı' veri tabanına kaydedilir.

Şekil 4

Tezgâhın anlık veri karşılaştırma algoritması 


\section{Veri Görselleme}

Üretim sahasında bulunan ve anlık üretim miktarını ve performans değerlerini gösteren ekranın tasarımında görünebilirlik ve sadelik öncelikli olarak ele alınmıştır. Ara yüz tasarımı yapılırken uzak mesafeden görülebilecek büyüklükte yazı tipi kullanılmıştır. Üretilecek miktar, hedef üretim miktarı ve üretilmiş olan miktar bu büyük yazı tipli ve uzaktan okunabilir değerlerdir. Performans göstergesinde işletmenin performans hedeflerine göre renk kodlaması yapılmıştır. Bu renk kodlamasında 3 adet renk kullanılmıştır. Bu renkler kırmızı, sarı ve yeşildir (Şekil 5).

Kırmızı renk Anlık performans değeri firmanın koyduğu \%80 sınırının altındaki performanslar için kullanılmaktadır. Firmayla yapılan görüşmelerde \%80'in altındaki performansın kabul edilemez olduğu belirtilmiştir. Sarı renk anlık performans değerinin firmanın belirttiği $\% 80$ sınırının üzerinde, fakat verimli üretim sınırı olarak değerlendirilen \%94'ün altında olduğu durumlarda kullanılmaktadır. Bu aralıktaki üretim kabul edilebilir değerlerdir fakat daha da iyileştirilebilir. Yeşil renk anlık performans değerinin \%94'ün üzerinde olduğu durumlarda kullanılan renk kodudur. Bu durumda üretim hedeflenen performansta gerçekleşmektedir.

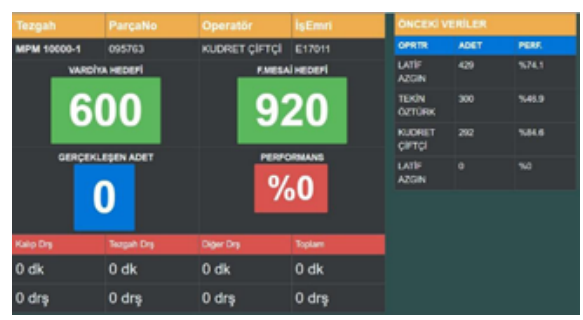

Şekil 5

Uygulama ara yüzü

\section{Tartışma ve Sonuç}

Çalışma kapsamında bir üretim tesisinin endüstri 4.0 hedeflerine ulaşması çerçevesinde nesnelerin interneti cihazları ile tezgâhlardan veri toplama ve anlık olarak analiz edilerek yöneticilerin daha etkin karar vermesi ve şirketin verimliliğinin artırılması sağlanmıştır. Bu çalışma kapsamında talaşlı üretim firmalarında BT kullanımının üretim performansını arttırıp arttırmadığını araştırılmıştır. İlk olarak üretim firmasında ihtiyaç analizi yapılıp işletmenin iş süreçleri ve istekleri göz önünde bulundurulmuş ve bir yazılım hazırlanmıştır.

Deneysel tasarım metodu kapsamında bir adet deney grubu (A tezgâhı), bir adet kontrol grubu (B tezgâhı) olacak şekilde iki adet üretim tezgâhı seçilmiştir. 1 Ocak 2016 ile 1 Aralık 2016 tarihleri arasındaki üretim performansı (Şekil 5) ortalamaları alınmıştır. $\mathrm{Bu}$ performans hesaplamasinın yapilmasının nedeni üretim tezgâhlarında çeşitli parçaların, farklı sürelerde üretilmesi ve bu değerlerin normalize edilip karşılaştırılabilir hale getirme ihtiyacıdır. Parça yapısı ve iş süreçleri gereği bir ürün 1 saatte 100 adet üretilebilirken diğeri 1 saatte 20 adet üretiliyor. Bu iki değeri ortak bir şekilde değerlendirmek için normalizasyon işlemi gerekmektedir. Normalizasyon sonucu her parça üretilmesi hedeflenen miktar kadar üretilirse 100 performansa ulaşacaktır. Üretilmesi hedeflenen miktar ve iş emri toplam süresi uygulama ise entegre çalışmakta olan üretim takip programlarındaki takip edilen tezgaha atanmış olan iş emirlerinden elde edilir. Hazırlanan uygulama işletmede kullanılan diğer üretim takip uygulamalarıyla dikey entegrasyona sahiptir. İş emri başlangıç ta- 
rihinden itibaren geçen süre olan geçen süre ve uygulama tarafindan hesaplanmış olan anlık üretim miktarı da kullanılarak anlık performans hesaplanır. Bu değer işletmenin anlık üretim performansının 100 üzerinden değerlendirilmesiyle oluşur (Şekil 6).

$$
\text { Performans }=100 \frac{\text { Gerçekte Uretilen Anık Miktar }}{\text { Oretilmesi Hedeflenen Miktar } \frac{\text { Geçen Süre }}{\text { Is Emri Toplam Sûre }}}
$$

Şekil 6. Performans hesaplama formülü

Belirtilen tarihler arasında A tezgâhının ortalama günlük performans1 $\% 96,77$ iken, B tezgâhının ortalama günlük performansı \%98,60 olarak hesaplanmıştır. Özellikleri ve ürettikleri ürün tipleri aynı olan bu iki tezgahtan deney grubu olan A tezgahına 1 Aralık 2016 tarihinde geliştirilen anlık üretim takip yazılımı ve sensör entegre edilmiştir.

Yazılımın kullanıldığ 1 Aralık 2016 tarihinden 1 Nisan 2017 tarihine kadarki dönemde A tezgâhında ve B tezgâhında yap1lan üretimin ortalama günlük performansı hesaplanmıştır. Belirtilen tarihler arasında A tezgâhının ortalama günlük performansı \%110,56'ya yükselmişken, B tezgâhının ortalama günlük performans1 $\% 106,64$ 'e yükselmiştir. Her iki tezgâhta da artış olmasıyla beraber A tezgâhındaki artış \%14,25 iken B tezgâhındaki artış \%8,14’te kalmıştır.

Yazılımın entegre edildiği 1 Aralık 2016 ile 1 Nisan 2017 arasındaki süreçte tezgâhlardaki üretimin artış veya azalış eğilimini görmek amacıyla her iki tezgâhın günlük üretim performansları grafiğe yerleştirilmiş ve Lineer Eğilim Çizgileri (Trend lines - Trend çizgileri) oluşturulmuştur (Şekil 7). Bu yöntem ile günlük üretim verisi grafiklerimiz 1 . dereceden bir denkleme indirgenerek pozitif veya negatif eğilimin olup olmadığ 1 görülebilir. Elde edilen denklemler şu şekildedir:

$$
\begin{aligned}
& \text { A tezgah } \rightarrow y=0.5893 x+88.87 \\
& \text { B tezgah } \rightarrow y=0.0644 x+102.04
\end{aligned}
$$

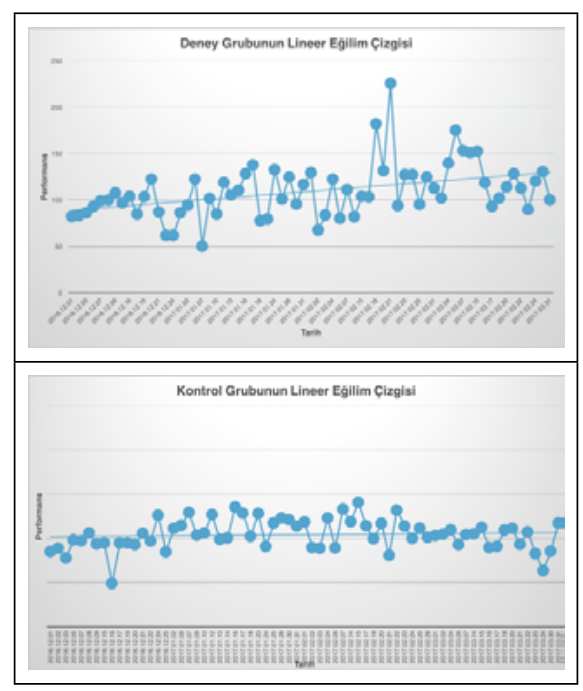

Şekil 7

Deney ve Kontrol Gruplarinin 4 Aylık Lineer Eğilim Çizgileri

Elde edilen denklemlerden ve Şekil 7'de yer alan eğilim çizgilerinden de anlaşıldığ gibi A makinesi 1 Aralık 2016'da daha düşük bir orijin değerinden başlamasına rağmen ilerleyen süreçte artan bir eğilim göstermiştir. B makinesi ise sabite yakın bir eğilim göstererek çok yavaş bir artış göstermektedir.

$$
\begin{aligned}
& \text { A tezgah } \rightarrow y=0.5893 x+88.87 \\
& \text { B tezgah } \rightarrow y=0.0644 x+102.04
\end{aligned}
$$




\begin{tabular}{cccccc}
\hline Tarih & Performans (\%) & Tezgâh & Parça No & Hedef Adet / Saat & Gerçekleșen Adet/Saat \\
\hline 2016.12 .01 & 99,74 & A TEZGAHI & F002339 & 65 & 65 \\
2016.12 .01 & 72,45 & A TEZGAHI & F002339 & 65 & 47 \\
2016.12 .15 & 106,59 & A TEZGAHI & F002339 & 65 & 69 \\
2016.12 .16 & 99,46 & A TEZGAHI & F002339 & 65 & 65 \\
2016.12 .16 & 103,27 & A TEZGAHI & F002339 & 65 & 67 \\
2016.12 .17 & 81,5 & A TEZGAHI & F002339 & 65 & 53 \\
2016.12 .17 & 96,61 & A TEZGAHI & F002339 & 65 & 63 \\
2016.12 .17 & 97,33 & A TEZGAHI & F002339 & 65 & 63 \\
2016.12 .17 & 109,66 & A TEZGAHI & F002339 & 65 & 47 \\
2017.01 .18 & 72,19 & A TEZGAHI & F002339 & 65 & 70 \\
2017.01 .19 & 106,97 & A TEZGAHI & F002339 & 65 & 70 \\
2017.01 .19 & 107,04 & A TEZGAHI & F002339 & 65 & 74 \\
2017.01 .19 & 113,98 & A TEZGAHI & F002339 & 65 & 71 \\
2017.01 .20 & 109,66 & A TEZGAHI & F002339 & 65 & 76 \\
2017.02 .17 & 126,51 & A TEZGAHI & F002339 & 65 & 76 \\
2017.02 .17 & 117,01 & A TEZGAHI & F002339 & 65 & \\
\hline
\end{tabular}

\section{Tablo 1}

F002338 numaralı parçanin hedeflenen, gerçekleştirilen ve performans verileri

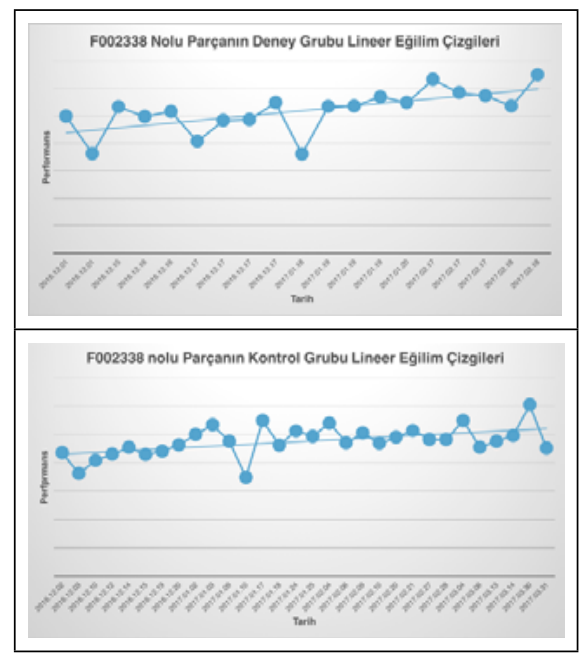

Şekil 8. F002338 nolu parçanın deney ve kontrol grubu lineer eğilim çizgileri

Daha detaylı sonuçlara varabilmek için anlık veri analizi yaklaşımının tek bir ürün üzerinde etkisini gözlemlemek amaciyla hem A hem de B tezgahında üretilmiş bir parçanın 1 Aralık 2016 ile 1 Nisan 2017 tarihleri arasında üretim verileri grafiğe yerleştirilmiştir. F002338 nolu parçanın üretim verilerinin artma veya azalma eğiliminde olup olmadığını gözlemlemek amacıyla lineer eğilim çizgileri oluşturulmuştur. Elde edilen lineer denklemler şu şekildedir:

$$
\begin{aligned}
& \text { A tezgah } 1 \rightarrow y=1.7728 x+86.058 \\
& \text { B tezgah } 1 \rightarrow y=0.6272 x+85.505
\end{aligned}
$$

Elde edilen lineer denklemlerden ve Şekil- 8 'de çizilmiş olan eğilim çizgilerinden anlaşıldığ gibi her iki tezgâhta da zaman içerisinde F002338 parçası üretiminde performans artışı görülmüşken, A makinesi belirtilen tarih aralığında $\mathrm{B}$ makinesine göre daha hızlı bir artış eğilimi göstermiştir. Elde edilen lineer denklemlerden ve Şekil- 8'de çizilmiş olan eğilim çizgilerinden anlaşıldığı gibi her iki tezgâhta da zaman içerisinde F002338 numaralı parçanın üretiminde performans artışı görülmüsşür. $\mathrm{Bu}$ genel artışın sebeplerinden birisi her tekrarlanan üretimde işletmenin ve operatörlerin parçayı daha iyi tanıması süreci daha iyi bilmesidir. Fakat veriler incelendiğinde A makinesi belirtilen tarih aralığında B makinesine göre daha hızıı bir artış eğilimi göstermiştir. (1,7728 eğim, 0,6272 eğim)

Tablo - 1'de grafikler ve lineer eğilimler oluşturulurken kullanılan veri setinden bir parça gösterilmiştir. Tabloda yer alan veri araştırmanın yapılmaya başlandığı 1 Aralık 
2016 tarihinden itibaren, deney grubu makinesi olan A tezgahında üretilen F002338 numaralı parçanın üretim verileri yer almaktadır. $\mathrm{Bu}$ üretim verileri belirtilen günlerde parçanın saatlik üretim hedefi ve belirtilen gün için ortalama saatlik gerçekleşen üretim miktarını gösterir. Performans sütununda ise günlük gerçekleşen üretim miktarının hedeflenen üretim miktarına oranı gösterilir (Şekil - 8).

$\mathrm{Bu}$ çalışmanın sonucunda deney grubu makinesi olan A tezgâhından elde edilen verilerin rastgele örneklem metoduyla elde edilmiş verilerin ortalama değeri $(\mu)=6216$, standart sapmas $(\sigma)=1669,154$ $\mathrm{n}=17$ ve $\mathrm{X}=6433,706$ olarak belirlenmiştir. Boş hipotezimizi test etmek için $Z_{h}$ değeri hesaplanmıştır. Yapılan hesaplama sonucu $Z_{h}=2,16562>Z_{0,05}=1,96$ elde edilmiştir. Böylelikle $\mathrm{H}_{0}$ hipotezimiz red edilerek, $\mathrm{H}_{1}$ hipotezimiz olan "Nesnelerin interneti ile anlık veri analizi ve raporlanması, üretim süreçlerinde verimliliği artırır." ifadesini doğrulamıştır. Yazılım kullanılan tezgâh aynı özelliklere sahip diğer tezgâha göre daha yüksek bir üretim artışı göstermiştir. Ayrıca sistem operatörlerin ve üretim şeflerinin üretimi anlık takip edebilmesini sağlamış, bu da gün içerisinde anlık performans düşüşlerini ve artışlarını gözler önüne sererek operatörlerin motivasyonunu arttırmıştır. Bu motivasyon artışı anketler yardımıyla daha detaylı bir şekilde başka bir çalışmada incelenebilir. Bu etki aynı özelliklere sahip, aynı operatörler tarafından yönetilen iki üretim tezgâhındaki üretim performansı artışındaki fark ile ortaya konulmuştur. Çalışma daha fazla üretim tezgâhı bulunan yüksek kapasiteli tesislerde de denenerek perfor- mans ölçümleri gerçekleştirilecektir. Yüksek kapasiteli ve daha fazla sayıda tezgâh daha büyük veri anlamına gelmektedir. $\mathrm{Bu}$ verinin analiz edilmesinde daha farklı yöntemler kullanılarak anlık veri analizi gerçekleştirilebilir. Sonuç olarak çalışmaya dahil olan işletmelerin çoğunda birbiri ile entegre sistemler kullanılmakla birlikte bunların yeterli olmadığı, daha dijital ve akıllı sistemlerin sorunların çözümünde etkili olacağı tespit edilmiştir.

\section{Kaynakça}

Aktaş F., Çeken C. ve Erdemli Y.E. (2014). Biyomedikal Uygulamaları için Nesnelerin İnterneti Tabanlı Veri Toplama ve Analiz Sistemi. Tip teknolojileri ulusal kongresi.

Atçı S., Alkan A., Eskikurt H. İ., Kolip A. (2015). Performans veri analizlerine bağlı olarak deneysel bir otomobil klima sisteminin kontrolü. Sakarya Üniversitesi Fen Bilimleri Enstitüsü Dergisi. Cilt:19 Sayı:2.

Aydın İ. (2012). Bilişim Sektörü Ve Türkiye'nin Sektördeki Potansiyeli. International Journal of New Trends in Arts, Sports \& Science Education.

EFİL İ., (2004). İşletme Yönetimi. Bursa: Alfa Akademi Yayınları.

Aydın C., Tarhan Ç., Tecim V. (2015). IT Based Vehicle Tracking System for Effective Management in Public Organizations. Procedia Economics and Finance. Vol: 33, Pages 506-517. DOI: $10.1016 / \mathrm{S} 2212-5671(15) 01733-5$

Bakır M., Aydoğan B., Aydın M., Khodabakhsh A., Ar1 İ., Ercan A. (2014). Rafinerilerdeki Büyük Veri Problemlerine Gerçek-Zamanlı Veri Uzlaştırma Çözümleri. IEEE 22nd Signal Processing and Communications Applications Conference.

Balkan D., Suiçmez H. (2007). Türkiye ve Dünya'da İşü̈cü Verimliliğinin Karşılaştırma11 Analizi. Verimlilik Dergisi. 
Brettel M., Friederichsen N., Keller M., Rosenberg M. (2014). How Virtualization, Decentralization and Network Building Change the Manufacturing Landscape: An Industry 4.0 Perspective. International Journal of Mechanical, Aerospace, Industrial, Mechatronic and Manufacturing Engineering Vol:8, No:1.

Can, A.V. ve Kıymaz M. (2016). Bilişim Teknolojilerinin Perakende Mağazacılık Sektörüne Yansimalari: Muhasebe Departmanlarinda Endüstri 4.0 Etkisi. Süleyman Demirel Üniversitesi Sosyal Bilimler Enstitüsü Dergisi

İncekara A., Mutlugün B., Yılmaz A. H. (2017). Borç Dolarizasyonunun Türk İmalat Sanayii Sektörü Büyümesi Üzerine Etkisi. İktisat Politikası Araştırmaları Dergisi. Cilt:4, Sayı:1, Sayfa:16-38

Kang, S; Chien, WTK; Yang, JG (2016). Study for Big-Data (Hadoop) Application in Semiconductor Manufacturing. IEEE International Conference on Industrial Engineering and Engineering Management. 1893-1897

Luo, H, Wang, K, Kong, XTR, Lu, SP, Qu, T. (207). Production and logistics via ubiquitous computing technology. Robotics and Computer-Integrated Manufacturing. Vol:45, 99-115
Melville N., Kraemer K. ve Gurbaxani V. (2004). Review: information technology and organizational performance: an integrative model of it business value. Review: information technology and organizational performance: an integrative model of it business value

Suiçmez H. (2017). Dünyada ve Türkiye'de verimlilikte son durum. Kalkınmada anahtar verimlilik dergisi. https://anahtar.sanayi.gov. $\mathrm{tr} / \mathrm{tr} /$ news/dunyada-ve-turkiyede-verimlilikteson-durum $/ 6270$

Schuh, G., Potente, T., Wesch-Potente, C., Weber, A. R., \& Prote, J. P. (2014). Collaboration Mechanisms to Increase. Productivity in the Content of Industrie 4.0. Robust Manufacturing Conference (s. 51-56). Elsevier

Weill P. (1992). The Relationship Between Investment in Information Technology and Firm Performance: A Study of the Valve Manufacturing Sector. Information System Research International Journal of New Trends in Arts, Sports \& Science Education - 2012, volume:1 Issue: 1

Vyatkin V., Salcic Z., Roop P. S., and Fitzgerald J. (2007). "Now That's Smart!," Industrial Electronics Magazine, IEEE, vol. 1, no. 4. pp. 17-29 